\title{
Defensive behavior of the rat in a shock-prod situation: Effects of the subject's location preference
}

\author{
HEIDAR A. MODARESI \\ University of Washington, Seattle, Washington 98195
}

\begin{abstract}
Experiment 1 investigated the proposition that rats cover the source of aversive stimulation with the bedding material available to them and sought to determine whether familiarization with this material would affect burying. The results indicated that rats are no more likely to cover an aversive object than they are not to cover it, although they collect a considerable amount of bedding material in the area surrounding the aversive object. Experiment 2 demonstrated that the rat's defensive "burying" toward an aversive object is affected by the subject's predisposition to displace material toward the front side of the apparatus. Some theoretical complexities involved in considering the act of "burying" toward an aversive object as a defensive behavior are discussed.
\end{abstract}

A dominant defensive behavior of a rat that is presented with an aversive object (e.g., a shock prod) appears to be to displace the bedding material available to it toward the aversive object (Pinel \& Treit, 1978, 1979; Pinel, Treit, Ladak, \& MacLennan, 1980; Pinel, Treit, \& Wilkie, 1980; Terlecki, Pinel, \& Treit, 1979; Treit, Pinel, \& Terlecki, 1980; Wilkie, MacLennan, \& Pinel, 1979). The defensive behavior in these situations has been conceptualized as "defensive burying" by these authors and has been used to imply either that the subject covers the aversive object (e.g., Terlecki et al., 1979; Pinel \& Treit, 1979) or that the subject's behavior is directed toward covering the aversive object (e.g., Pinel $\&$ Treit, 1978, 1979; Terlecki et al., 1979). A methodological consideration of these studies, however, indicates that neither of these implications has clear experimental support. On the one hand, these investigators have never demonstrated that the experimental subject does, in fact, cover the aversive object. On the other hand, the dependent measures used by these investigators would not even allow the conclusion that the movement of material ("spraying") is necessarily directed at the aversive object. The following measures of defensive "burying" have been used in these studies: (1) Duration of defensive burying (e.g., Pinel \& Treit, 1978; Pinel, Treit, \& Terlecki, 1980)-This measure involves measurement of the time intervals that the subject spends moving the bedding material; the direction of spraying

This research was supported by National Science Foundation Grant BNS-76-19912 to Robert C. Bolles, whom the author would like to thank for his support during the course of this study. This study was conducted while the author was a research associate at the University of Washington. Requests for reprints should be sent to H. A. Modaresi, who is now in the Department of Psychology, Winthrop College, Rock Hill, South Carolina 29733. has never been precisely identified, but rather is normally described in an anecdotal fashion. It is, therefore, impossible to determine, on the basis of these articles, whether "burying" refers only to spraying toward the aversive object, and if so, how the direction of spraying is determined. In a few studies (e.g., Pinel \& Treit, 1979), spraying toward an aversive prod was rated by several observers, and the interraters correlation was reported to be nearly perfect. Unfortunately, the investigators failed to report whether the raters were blind to the experimental conditions. (2) Height of the pile of the bedding material that the subject presumably accumulates at the prod (e.g., Pinel \& Treit, 1978; Wilkie et al., 1979)-Again, this measure is not adequately defined: How far from the ends or either side of the prod is considered to be "at" the prod? This question is important, since a subject's spraying may be directed at the special cues that are associated with the location of the aversive object and not at the prod per se (Pinel, Treit, \& Wilkie, 1980). (3) The ratio of the height of the pile the subject makes with the bedding material to the pile's distance from the aversive prod (Pinel \& Treit, 1978)-This measure is adopted because it is presumed to vary inversely with the distance and directly with the amount of spraying toward the prod. This presumption, however, is not necessarily true, since a subject may conceivably make considerably higher piles farther away from the prod.

In light of the above discussion, it is clear that none of the dependent measures in the above studies could project an unambiguous picture of what the animal does when it "buries." In particular, it is very unclear in these studies whether the subject actually covers the aversive object. One purpose of the present studies, therefore, was to determine whether the sub- 
ject would, in fact, cover a source of aversive stimulation. A second purpose was to investigate the effects of familiarizing the subjects in groups to the bedding material inside the experimental chamber (Pinel's studies on "defensive burying" routinely employ a familiarization phase in which the subjects are exposed in groups to the bedding material inside the experimental chamber). In addition, the present studies examined the importance of the spatial cues (i.e., location of) associated with the aversive object. Specifically, since rats are often placed in the experimental chamber through the front side and since rats readily respond to spatial and extra-apparatus cues (Olton \& Isaacson, 1968; Olton \& Samuelson, 1976), they may not be neutral toward the side of the chamber in which an aversive object is placed. None of the previous experiments on defensive burying has controlled for the effects of this variable. One purpose of the present studies was to investigate the role of this variable.

\section{EXPERIMENT 1}

This experiment replicated the basic procedures of defensive burying experiments as conducted by Pinel and his associates (e.g., Pinel \& Treit, 1978) to determine whether the subjects actually covered an aversive object. In addition, it investigated the effect on defensive spraying of familiarizing the subject in groups to the bedding material inside the experimental chamber.

\section{Method}

Subjects and Apparatus. The subjects were 27 male hooded rats from the animal colony of the Psychology Department at the University of Washington. They were 105-163 days old, were housed in groups of four or five per cage, and had free access to food and water. The apparatus consisted of a $24 \times 24 \times 15 \mathrm{~cm}$ high clear Plexiglas chamber with a wooden floor. The front wall was hinged to the adjacent side wall at one end and served as the door to the apparatus. The floor was divided, by drawing two perpendicular lines, into four identical $12 \times 12 \mathrm{~cm}$ quadrantsfront left, front right, back left, and back right (FL, FR, BL, and $B R$, respectively). A wooden prod, $1 \mathrm{~cm}$ in diameter and $7 \mathrm{~cm}$ in length, was mounted inside the chamber through a fitting hole at the midline of the FL quadrant side wall $5 \mathrm{~cm}$ above the floor. The prod was firmly held in place by a set of clamps outside the chamber. The prod was wrapped with two uninsulated copper wires, $2 \mathrm{~mm}$ apart. The wires were connected to a constant current shocker that could deliver a shock of $4.5-\mathrm{mA}$ intensity. The experiment was conducted under normal fluorescent ceiling light.

Procedure. The basic procedures were similar to those employed in the defensive burying studies conducted by Pinel and his associates, and consisted of two consecutive phases. Phase 1 (familiarization) consisted of placing the subject inside the chamber for 30 min on 4 consecutive days while shock was disconnected from the prod. The subjects were assigned randomly to three groups of nine rats each. These groups differed only in terms of the treatments they received in Phase 1: whether or not they were familiarized with the bedding material (San-i-cel bedding material, Paxton Processing Co., Paxton, Illinois) and whether they were placed inside the chamber in groups of three or one at a time. The amount of handling was similar for all subjects, and was confined to trans- porting the subjects between the home cage and the experimental chamber during both phases of the experiment. The subjects in the group-familiar group (GF) were familiarized in groups of three at a time with the bedding material inside the experimental chamber. The subjects in the single-familiar group (SF) received identical treatment, except that they were placed inside the chamber one at a time. The floor of the chamber for both of these groups was evenly covered with $400 \mathrm{~g}$ of bedding material. A comparison of defensive behavior in these groups should reveal possible effects of group manipulation during the familiarization phase. The subjects in the single-unfamiliar group (SU) were placed inside the chamber one at a time, with the chamber containing no bedding material. Thus, the SU group was not familiar with the bedding material. Comparison of defensive behavior in this group and the SF group should reveal the effects of familiarization with the bedding material.

In Phase 2 (testing), which began 1 day after the last session of Phase 1, the subjects in all three groups were placed singly inside the experimental chamber, the floor of which was evenly covered with $400 \mathrm{~g}$ of bedding material. The top of the bedding material was about $2.0 \mathrm{~cm}$ below the prod. As soon as a subject made contact with the prod wires with both of its front paws, the wires were electrified for $.5 \mathrm{sec}$. The actual duration of shock received by the subject, however, varied, depending upon the duration of subject's contact with the prod wires. The subject was observed throughout Phase 2 (for 15 min following prod shock) from a distance of $2 \mathrm{~m}$ in front of the apparatus, with attempts being made not to disturb the subject. The following indices of the subject's defensive spraying were recorded: the time after shock delivery until the prod was completely covered; the number of subjects that, at any time during Phase 2, covered the prod; the weight of the bedding material in the prod quadrant (i.e., FL) at the end of testing.

\section{Results}

Table 1 presents the results of Experiment 1 in terms of three different, but not necessarily independent, measures. The first measure, the amount of bedding material collected in the prod quadrant, was similar for all three groups. This was confirmed by the results of a one-way analysis of variance $[F(2,24)$ $<1]$. Subsequent $t$ tests on the data of each group indicated that the amount of bedding material in the prod quadrant was significantly greater at the end than at the start of testing (i.e., more than $100 \mathrm{~g}$ ) (all ps $<.05$ ). These results suggest that rats spray and shove bedding material in the direction of an aversive object and that these behaviors are not affected by familiarizing the subjects, in groups or individually, to the bedding material in the chamber.

Table 1

Indices of Defensive Behavior Toward a Shock Prod in Different Groups

\begin{tabular}{llll} 
& \multicolumn{3}{c}{ Group } \\
\cline { 3 - 5 } Dependent Measures & SF & GF & GU \\
\hline $\begin{array}{l}\text { (1) Mean weight* of bedding } \\
\text { material in prod quadrant }\end{array}$ & 147.88 & 153.44 & 144.75 \\
$\begin{array}{l}\text { (2) Percentage of subjects leaving } \\
\text { prod entirely uncovered }\end{array}$ & 33.33 & 44.44 & 33.33 \\
$\begin{array}{l}\text { (3) Percentage of subjects leaving } \\
\text { prod partly covered }\end{array}$ & 22.22 & 0.00 & 33.33 \\
\hline
\end{tabular}

-In grams. 
The remaining dependent measures in Table 1 , however, suggest that rats do not necessarily cover the aversive object. Specifically, although the subjects in all groups sprayed in the direction of the prod quadrant, as indicated by observation of the subject and by dependent measure 1 in Table 1 , measures 2 and 3 indicate that less than half of the SF or GU subjects and only slightly more than half of the GF subjects had the prod covered by the end of testing. The remaining subjects left the prod either entirely exposed (measure 2) or partly covered (measure 3 ). None of the subjects that left the entire prod uncovered by the end of testing in any of the groups ever covered the prod during testing. Because of the small number of subjects involved, the number of subjects in each group that covered the prod and the number of those that left the prod entirely uncovered were subjected to Kolmogorov-Smirnov test. No significant results were obtained (all ps $<.05$ ), indicating that there was no difference, in any group, between the number of subjects that buried and the number that did not bury the prod.

The present results indicate that a subject is as likely to cover an aversive object as it is to leave it entirely uncovered within the time limit of the present testing period. Whether or not the subject is familiarized with the bedding material does not change this conclusion. Considering the fact that the rats accumulated a large amount of bedding material in the prod quadrant (measure 1 in Table 1 ), the present results suggest that rats spray and shove bedding material toward the general direction of an aversive object, but do not necessarily cover it. These results are harmonious with the recent findings (Pinel, Treit, \& Wilkie, 1980 ) that the rat's burying behavior is controlled by both the stimulus and the position (spatial) cues of an aversive object. Specifically, since both the spatial cues (e.g., location with respect to the extra-apparatus cues) and the stimulus cues of an aversive object may elicit burying and thus compete for the amount of bedding material available, the amount of bedding material sprayed at the aversive object per se may not be sufficient to cover it. The bedding material may, therefore, only be displaced toward the general direction of the aversive object.

\section{EXPERIMENT 2}

Pinel, Treit, and Wilkie (1980), as mentioned earlier, have demonstrated that the rat's burying behavior is controlled by the stimulus and the spatial (position) cues of an aversive object. No distinction was made in these studies between the cues associated with different possible locations of the aversive object. That is, the subjects were assumed to have no initial preference for spraying toward one side or another of the experimental chamber. In fact, this same assumption has been tacitly made in all previous studies of defensive spraying, since in none has the location of the aversive object been considered to be a factor. The results of a pilot study in the present laboratory, however, suggested that this might not be a tenable assumption. Specifically, rats seem to have a strong predisposition to spray toward the front side of a chamber. The reason for this preference was not evident, but it was thought to be possibly related to the experimental procedures of subject handling and placement inside the chamber through the front side. The experimenter, in this case, is an intruder, and the subject may, by blocking the front side of the chamber with the bedding material, be warding off the visual cues associated with him. If the existence of such a variable were substantiated, then some, if not all, previous studies on defensive spraying might have to be reinterpreted, since none of them included an appropriate control treatment.

Experiment 2 investigated the effects of the location of a shock prod on the magnitude of the rat's defensive spraying. Basically, the present study replicated the procedures of a standard prod-burying study, as introduced by Pinel and Treit (1978), except that groups of subjects were treated differently with respect to the location of the prod during both phases of the experiment. Specifically, during familiarization the prod was in either the FL or BR quadrant, or in none of the quadrants and during testing it was in the FL or BR quadrant. Exposure of subjects to the prod during familiarization was expected to result in a latent inhibitory process with respect to the subsequent fear conditioning to the prod (Lubow, 1973; Lubow \& Siebert, 1969). Defensive spraying in the subjects that received no habituation to the prod during familiarization was expected to reflect the effects of both the prod and the spatial cues. On the other hand, defensive spraying in the habituated subjects should, because of the weakened effects of the prod cues through a latent inhibitory process, primarily reflect the effects of spatial cues.

\section{Method}

Subjects and Apparatus. Forty-eight male hooded rats, 120-159 days old, from the same colony as in Experiment 1 were used. The apparatus was the one used in Experiment 1.

Procedure. As in Experiment 1, the experimental procedures consisted of two consecutive phases. In Phase 1 (habituation), the subjects were divided randomly into three groups of 16 rats each and were placed, in groups of 4 , into the apparatus for four daily 30 -min periods. The floor of the apparatus was evenly covered with $400 \mathrm{~g}$ of regular grade San-i-cel bedding material. For one of the three groups, a wooden prod, which was $7 \mathrm{~cm}$ long, $1 \mathrm{~cm}$ in diameter, and wire-wrapped with two uninsulated copper wires, was mounted in the side wall at the midline of the FL quadrant. For the second group, the prod was located in the corresponding location of the BR quadrant. The prod was $2 \mathrm{~cm}$ above the bedding material. For the third group there was no prod during habituation. The amount of bedding material the subjects in all three groups had accumulated in each quadrant by the end of a habituation 
period was recorded. The animals were placed inside the chamber through the front side, a clear Plexiglas door.

In Phase 2 (testing), each of the three groups was subdivided in two subgroups, and each subgroup received a prod shock in either the FL or BR quadrant. Thus, there were six groups, FL/N, BR/N, FL/FL, BR/FL, FL/BR, and BR/BR. The first set of letters in each group name designates the quadrant in which the subject experienced a prod shock during testing, and the second set of letters refers to the location (BR or FL quadrant) or absence $(N)$ of the prod during habituation. A testing period began with the placement of a subject on the bedding material, in the center of the apparatus, facing away from the prod. As soon as the subject made contact with the prod with both of its front paws, the wires on the prod were electrified for $.5 \mathrm{sec}$. The shock intensity was set at $4.5 \mathrm{~mA}$. The testing period lasted for $15 \mathrm{~min}$ after the shock delivery. During this time the experimenter was absent from the room and the subject was entirely undisturbed. The amount of bedding material in each quadrant at the end of testing was measured for each subject.

\section{Results and Discussion}

Figure 1 presents, for each group, the mean weight of bedding material accumulated at each quadrant over the entire habituation sessions. Since habituation took place with groups of four subjects at a time, individual subject's data could not be determined, and no statistical analysis could, therefore, be performed on these data. A visual impression of the data in Figure 1 indicates that the trends in the accumulated bedding material in the various quadrants are strikingly similar for all three groups. In all groups, the amount of bedding material in the front quadrants exceeded the original amount of $100 \mathrm{~g}$, while the op-

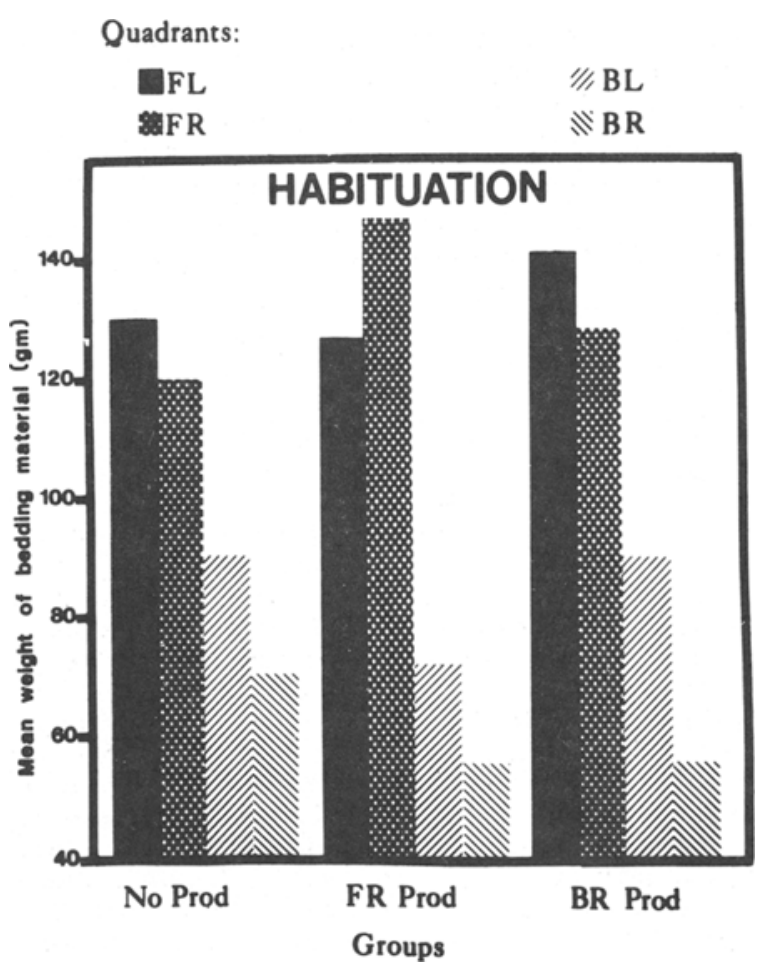

Figure 1. Mean weight of bedding material in different quadrants over all habltuation sessions.

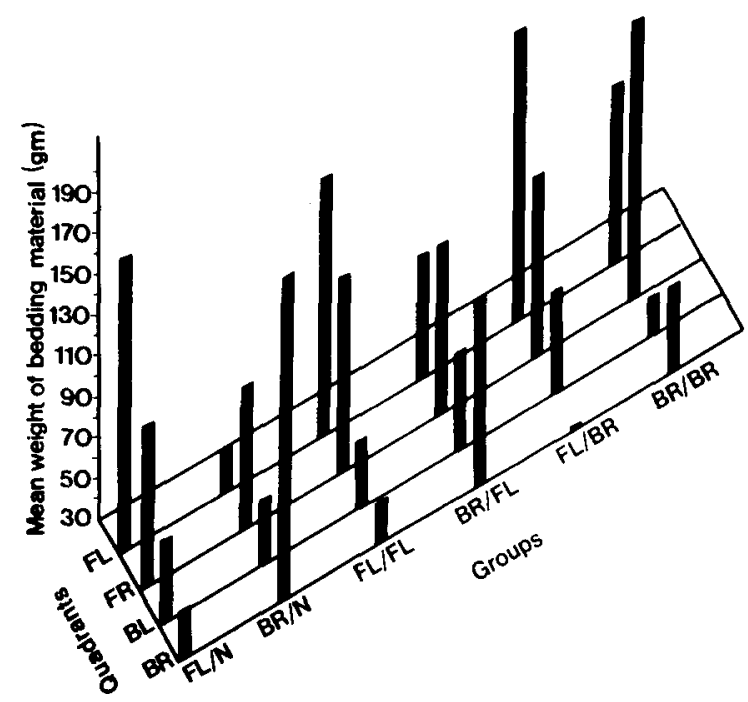

Figure 2. Mean weight of bedding material in different quadrants at the end of testing, for each group.

posite was true for the back quadrants. These findings suggest that rats enter the experimental situation not as neutral agents, but with a definite predisposition to displace the bedding material toward the front side of the apparatus.

Figure 2 presents the results of Experiment 2 in terms of the mean weight of bedding material that was accumulated in each quadrant at the end of testing. These data suggest that the subjects who experienced a prod shock in the FL quadrant (FL/N, FL/FL, and FL/BR groups) accumulated a relatively large amount of bedding material at the prod quadrant, primarily with the bedding material from the BR quadrant. The bedding material in the other front quadrant, FR, was not, in any of these groups, below the original level of $100 \mathrm{~g}$. With the shock prod in the FL quadrant, therefore, the habituation condition did not seem to make any difference in the amount of accumulated bedding in the prod quadrant.

When the shock prod was located in the BR quadrant (BR/N, BR/FL, and BR/BR groups), however, the amount of accumulated bedding material seemed to depend on the habituation condition. Specifically, while the BR/N subjects accumulated a substantial amount of bedding material in the shock prod quadrant, the BR/FL subjects accumulated only a small amount of bedding in the prod quadrant and, for the BR/BR group, the level of bedding material in the prod quadrant had fallen below its original level.

The amount of bedding material at the shock prod quadrants was subjected to a $2 \times 3$ factorial analysis of variance with shock-prod location (FL and BR quadrants) and habituation condition (prod at FL or BR quadrant or no prod) as the factors. This analysis resulted in significant effects of shock prod location $[F(1,42)=9.79]$, habituation condition $[F(2,42)=6.12]$, 
and the interaction between these factors $[F(2,42)$ $=6.70$; all ps $<.002]$. Since the interaction effect was significant, Newman-Keuls tests $(\alpha=.05)$ were conducted on group means. The results of these tests indicated that the BR/BR group accumulated less bedding material in the shock prod quadrant than any of the other groups except the BR/FL group. The BR/FL group, in turn, collected less bedding material in the shock prod quadrant than the BR/N group. No other difference was significant. A t test on the data of each group tested the null hypothesis that the amount of bedding material in the shock prod quadrant was no different from the initial amount of $100 \mathrm{~g}$. The results indicated that the accumulated bedding material was significantly greater than $100 \mathrm{~g}$ for Groups FL/N, FL/FL, FL/BR, and BR/N, but not for Group BR/FL. The amount of accumulated bedding material for the $B R / B R$ group was significantly lower than $100 \mathrm{~g}$ (all ps $<.05$ ).

The present findings support the contention that the rat's predisposition to spray toward some spatial cues in the apparatus may play a considerable role in the rat's defensive spraying. Although the effect of this subject variable was not evident in a simple defensive arrangement, as a comparison between the FL/N and $\mathrm{BR} / \mathrm{N}$ groups demonstrates, a more sensitive habituation treatment revealed the putative effect. With the latter procedures, habituation resulted in little or no accumulation of bedding material toward the shock prod if it was located at the back wall of the chamber (i.e., BR/FL and BR/BR groups). However, when the shock prod was located in a front quadrant, the subject's tendency to spray toward it masked the inhibitory effects of habituation (i.e., the FL/FL group compared with the FL/BR group).

\section{GENERAL DISCUSSION}

Pinel and his associates have argued that "rats will approach a source of aversive stimulation and bury it" (Pinel \& Treit, 1978, p.5). To the extent that these authors conceive of "burying" as covering the source of aversive stimulation (e.g., Pinel \& Treit, 1979; Terlecki, Pinel, \& Treit, 1979), they are yet to present an experiment that would specifically corroborate their hypothesis. Unfortunately, the dependent measures of defensive burying used by these authors do not clearly reveal the direction in which bedding material is displaced, or where, in relation to the aversive object, a pile of bedding is accumulated, or to what extent the aversive object is covered.

The present results indicate that the contention that "defensive burying" consists of either spraying toward or covering the source of aversive stimulation is a simplistic view of the rat's defensive behavior. These results demonstrate that rats do not necessarily cover an aversive object, although they may spray and shove material toward it. They also indicated that the nature of the defensive reaction of a rat toward an aversive object is subject to further qualifications, namely, the subject's behavioral tendencies prior to the experimental treatment.

Thus, the subjects in Experiment 2, who showed a strong predisposition for spraying toward the front side of the experimental chamber, were immune to the inhibitory effects of habituation to the aversive prod only when, during testing, it was located in the front side. Located in the back side, the prod shock elicited no spraying in the habituated subjects. This finding raises the question of whether spraying toward an aversive object is, in fact, defensive. Since the subject may enter the experimental situation with a tendency to spray the bedding material, it is entirely possible that aversive stimulation increases the subject's general drive level and, thereby, potentiates an already existing behavioral tendency (Hull, 1943; Kendler, 1945). Whether or not spraying toward an aversive object is defensive may, therefore, depend on the function of "unconditioned" spraying in the subject. Thus, in order to demonstrate that spraying toward a shock prod is a defensive behavior, rather than a potentiated tendency other than defense, for example, play or frustration, it may be necessary to demonstrate that the initial spraying has a defensive function. Unfortunately, the function of this response in the rat's natural behavior repertoire is not known. On the other hand, one may correctly argue that spraying toward an aversive object may be defensive regardless of the function of the initial spraying. In the present studies, it is likely that the subject's unconditioned spraying toward the front side of the chamber may have actually been defensive against the experimenter. The fact that the experimenter handled the subjects, a treatment that seems to be aversive to rats (McAllister, McAllister, Hampton, \& Scoles, 1980), and the possibility that the experimenter might have been seen by the subject through the front side while moving the subject into and out of the chamber, renders the present suggestion a viable possibility.

\section{REFERENCES}

Huld, C. L. Principles of behavior. New York: Appleton-CenturyCrofts, 1943.

KENDLER, H. H. Drive interaction: II. Experimental analysis of the role of drive in learning theory. Journal of Experimental Psychology, 1945, 35, 188-198.

Luвow, R. E. Latent inhibition. Psychological Bulletin, 1973, 79, 398-407.

Lubow, R. E., \& Siebert, L. Latent inhibition within the CER paradigm. Journal of Comparative and Physiological Psychology, 1969, 68, 136-138.

McAlliste k, D. E., McAllister, W. R., Hampton, S. R., \& Scoles, M. T. Escape-from-fear performance as affected by handling method and an additional CS-shock treatment. Animal Learning \& Behavior, 1980, 8, 417-423. 
Olton, D. S., \& IsAacson, R. L. Importance of spatial location in active avoidance tasks. Journal of Comparative and Physiological Psychology, 1968, 65, 535-539.

Olton, D. S., \& Samuelson, R. J. Remembrance of places past. Spatial memory in rats. Journal of Experimental Psychology: Animal Behavior Processes, 1976, 2, 97-116.

PINEL, J. P. J., \& TREIT, D. Burying as a defensive response in rats. Journal of Comparative and Physiological Psychology, 1978, 92, 708-712.

Pinel, J. P. J., \& Treit, D. Conditioned defensive burying in rats: Availability of burying materials. Animal Learning \& Behavior, 1979, 7, 392-396.

Pinel, J. P. J., Treit, D., Ladak, F., \& Maclennan, A. J. Conditioned defensive burying in rats free to escape. Animal Learning \& Behavior, 1980, 8, 447-451.
Pinel, J. P. J., Treit, D., \& Wilkie, D. M. Stimulus control of defensive burying in the rat. Learning and Motivation, 1980, 11, 150-163.

Tertecki, L. J., Pinel, J. P. J., \& Theit, D. Conditioned and unconditioned defensive burying in the rat. Learning and Motivation, 1979, 10, 337-350.

Treit, D., Pinel, J. P. J., \& Terlecki, L. J. Shock intensity and conditioned defensive burying in rats. Bulletin of the Psychonomic Society, 1980, 16, 5-7.

Wilkie, D. M., Maclennan, A. J., \& Pinel, J. P. J. Rat defensive behavior: Burying noxious food. Journal of the Experimental Analysis of Behavior, 1979, 31, 299-306.

(Manuscript received May 28, 1981; revision accepted for publication November 3,1981 .) 